\title{
Bone marrow and peripheral blood expression of ID I in human gastric carcinoma patients is a bona fide indicator of lymph node and peritoneal metastasis
}

\author{
M Iwatsuki',2, T Fukagawa ${ }^{3}, K_{\text {Mimori }}{ }^{1}$, H Nakanishi ${ }^{4}$, S Ito ${ }^{5}$, H Ishii', T Yokobori', M Sasako ${ }^{3}$, H Baba $^{2}$ \\ and $M$ Mori*,i
}

'Department of Surgical Oncology, Medical Institute of Bioregulation, Kyushu University, 4546 Tsurumihara, Beppu 874-0838, Japan; ${ }^{2}$ Department of Gastroenterological Surgery, Graduate School of Medical Sciences, Kumamoto University, I I - I Honjo, Kumamoto 860-8556, Japan; ${ }^{3}$ Gastric Surgery Division, National Cancer Center Hospital, 5-I-I Tsukiji, Chuo-ku, Tokyo 104-0045, Japan; ${ }^{4}$ Division of Oncological Pathology, Aichi Cancer Center Research Institute, I-I Kanokoden, Chikusa-ku, Nagoya 464-868I, Japan; ${ }^{5}$ Department of Gastroenterological Surgery, Aichi Cancer Center Central Hospital, I-I Kanokoden, Chikusa-ku, Nagoya 464-868I, Japan

\begin{abstract}
Recent studies have showed that the bone marrow-derived endothelial progenitor cells play critical roles in metastasis and that ID I is required in metastasis as regulator of angiogenesis. Therefore, we investigated the clinical significance of ID / mRNA expression in bone marrow and peripheral samples in patients with gastric cancer. Two hundred and eighty-nine bone marrow and I 96 peripheral blood samples from gastric cancer patients were collected and analysed by quantitative RT-PCR for ID I. The IDI protein expression in one bone marrow, three metastatic lymph nodes and three peritoneal disseminated tumours was examined by immunohistochemical methods. In both bone marrow and peripheral blood samples, IDI mRNA expression in the metastatic group was significantly higher than in any other group $(P=0.003, P=0.000 \mathrm{I}$, respectively) and significantly associated with lymph node metastasis and peritoneal dissemination. The cells in bone marrow with metastatic cancer stained strongly with IDI compared with those of healthy volunteers. The expression of ID I mRNA in bone marrow and peripheral blood was significantly associated with lymph node metastasis and peritoneal dissemination, and therefore constitutes a predictable marker for lymph node metastasis and peritoneal dissemination.
\end{abstract}

British Journal of Cancer (2009) 1 00, 1937-1942. doi:I0.1038/sj.bjc.6605085 www.bjcancer.com

Published online 2 June 2009

(c) 2009 Cancer Research UK

Keywords: ID /; gastric cancer; bone marrow; peripheral blood; lymph node metastasis; peritoneal dissemination

The presence of isolated tumour cells (ITCs) is an important factor in the metastasis of solid cancers. Recently, we investigated the presence of ITCs in peripheral blood and in bone marrow, using quantitative RT-PCR in more than 800 cases of gastric cancer (Mimori et al, 2008). We found that ITCs circulate in a range of clinical stages of gastric cancer. These data suggested that host cells might play a supportive role for metastasis.

Recently, Kaplan et al reported that bone marrow-derived haematopoietic progenitor cells that express vascular endothelial growth factor receptor 1 (VEGFR-1) home to tumour-specific pre-metastatic sites and form cellular clusters before the arrival of tumour cells (Kaplan et al, 2005). In a large-scale study of gastric cancer cases, we recently reported that the simultaneous expression of ITC-associated genes and high levels of expression of VEGFR-1 in bone marrow were significantly associated with haematogeneous metastases (Mimori et al, 2008). Gao et al determined that the bone marrow-derived endothelial progenitor cells (EPCs) were critical regulators of angiogenic switching (Gao et $a l, 2008)$. Furthermore, they showed that tumours induce expression of ID1 in EPCs and that suppression of ID1 after

*Correspondence: Dr M Mori; E-mail: mmori@gesurg.med.osaka-u.ac.jp Received 12 November 2008; revised I April 2009; accepted 8 April 2009; published online 2 June 2009 metastatic colonisation blocked EPC mobilisation, inhibited angiogenesis and impaired pulmonary macrometastases. ID proteins are inhibitors of DNA binding of basic helix-loop-helix (bHLH) transcription factors by heterodimerisation with the bHLH proteins (Benezra et al, 1990). ID1 has been reported to be associated with the undifferentiation of cancer cells, severe malignant grade of tumour, invasion of tumours and worse prognosis in several tumours (Fong et al, 2003).

In this study, we investigated the clinical significance of the ID1 mRNA expression in bone marrow and peripheral blood samples obtained from gastric cancer patients. The results showed that the ID1 mRNA expression in bone marrow and peripheral blood was significantly associated with lymph node metastasis and peritoneal dissemination. Thus, ID1 is a bona fide predictive marker for both pathologic parameters, each of which is an established definitive prognostic indicator in gastric cancer.

\section{MATERIALS AND METHODS}

\section{Patients}

Physicians (TF and MS) collected bone marrow and peripheral blood samples from 289 Japanese gastric cancer patients who underwent surgery from 2001 to 2004 at the Central Hospital, the 
Table I Clinicopathlogial significance of ID/ mRNA expression in gastric cancer patients

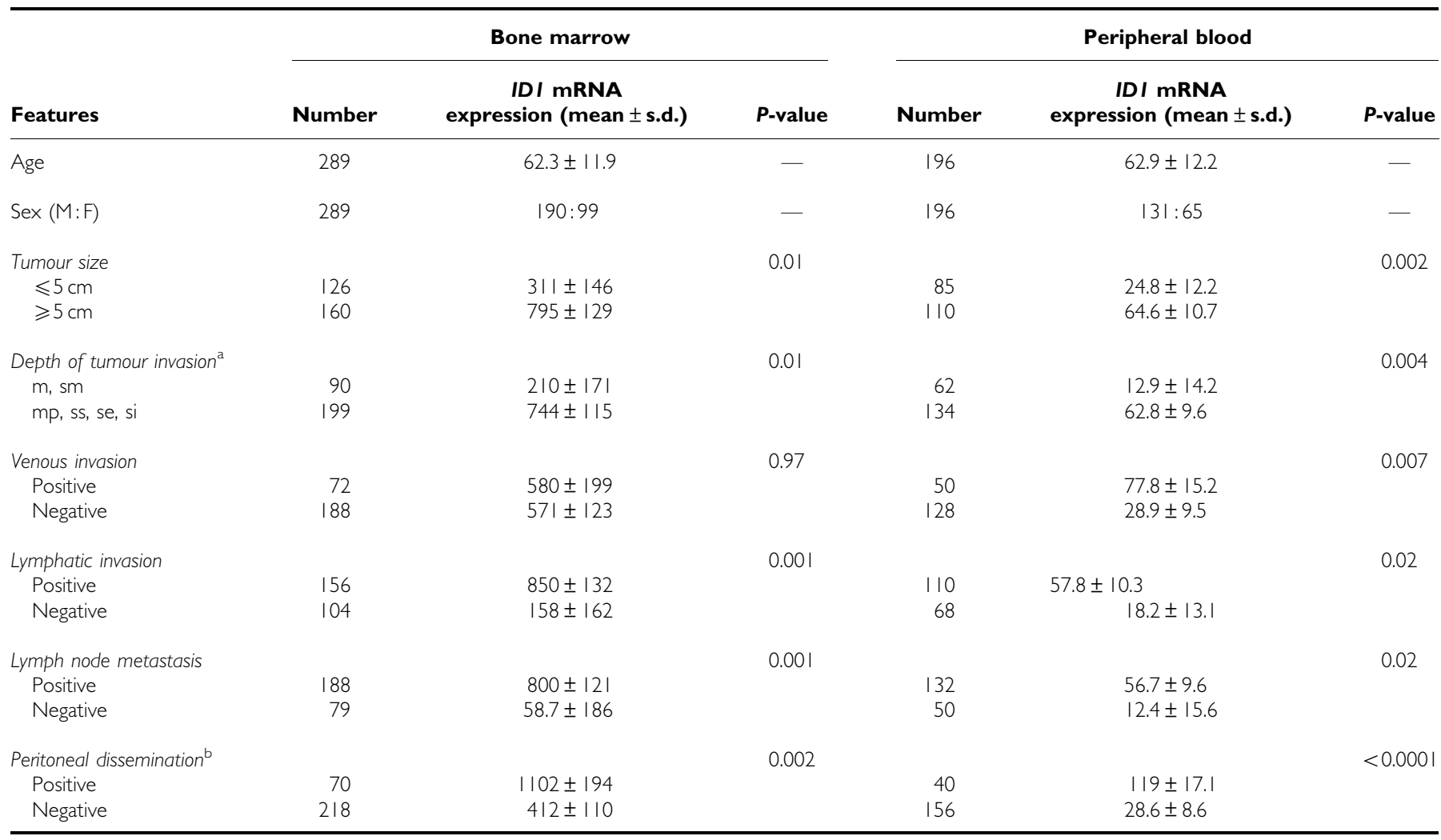

${ }^{a}$ Tumour invasion of mucosa $(\mathrm{m})$, submucosa $(\mathrm{sm})$, muscularis propria $(\mathrm{mp})$, subserosa (ss), penetration of serosa (se) and invasion of adjacent strucures (si). ${ }^{\mathrm{b}}$ Peritoneal dissemination: peritoneal cytology or metastasis positive.

National Cancer Center, Tokyo, Japan. The documented informed consent was obtained from all patients and the protocol of the study was approved by the local ethics committee. There were 190 male and 99 female patients with an average age of 62.3 and a range of 24-86 years (Table 1). Seventy of the patients showed peritoneal dissemination at the time of surgery or at postoperative follow-up. Among the 289 cases, 76, 60, 62 and 91 were classified as stages I, II, III or IV, respectively, according to the Treaty for Japanese Gastric Cancer Association (Maruyama et al, 2006).

\section{Bone marrow and peripheral blood samples from gastric cancer patients}

Aspiration of both bone marrow and peripheral blood was conducted under general anaesthesia immediately before surgery as described earlier (Mimori et al, 2008). The bone marrow aspirate was obtained from the sternum using a bone marrow aspiration needle and peripheral blood was obtained through a venous catheter. The first $1.0 \mathrm{ml}$ of bone marrow and peripheral blood were discarded to avoid contamination by the skin. The second collected $1.0 \mathrm{ml}$ of bone marrow and peripheral blood were put into $4.0 \mathrm{ml}$ of Isogen-LS (Nippon Gene, Toyama, Japan) and stored at $-80^{\circ} \mathrm{C}$ until RNA extraction.

\section{Total RNA extraction and first-strand cDNA synthesis}

Samples transferred from Tokyo to Beppu remained frozen while in transit. Total RNA was extracted from bone marrow and peripheral blood according to the manufacturer's protocol as described elsewhere (Iinuma et al, 2006). The reverse transcriptase reaction (RT) was performed as described earlier (Mori et al, 1995). The first-strand cDNA was synthesised from $2.7 \mu \mathrm{g}$ of total
RNA in $30 \mu \mathrm{l}$ reaction mixtures containing $5 \mu \mathrm{l} 5 \times \mathrm{RT}$ buffer (BRL, Gaithersburg, MD, USA), $200 \mu \mathrm{M}$ dNTP, a $100 \mu \mathrm{m}$ solution of a random hexadeoxynucleotide mixture, 50 units of Rnasin (Promega, Madison, WI, USA), $2 \mu \mathrm{l}$ of $0.1 \mathrm{~m}$ dithiothreitol and 100 units of Maloney leukemia virus RT (BRL). The mixture was incubated at $37^{\circ} \mathrm{C}$ for $60 \mathrm{~min}$, heated to $95^{\circ} \mathrm{C}$ for $10 \mathrm{~min}$ and then chilled on ice.

\section{Quantitative real-time RT-PCR}

The sequences of ID1 mRNA were as follows: sense, 5'-CC AGTGGCAGCACCGCCACC-3', and anti-sense, 5'-CGGATTCCG AGTTCAGCTCC- $3^{\prime}$. We used glyceraldehyde-3-phosphate-dehydrogenase $(G A P D H)$ as an internal control. The primers were as follows: sense, $5^{\prime}$-TTGGTATCGTGGAAGGACTCTA-3' ${ }^{\prime}$, and antisense, 5'-TGTCATATTTGGCAGGTT-3'. Real-time monitoring of PCR reactions was performed using the LightCycler system (Roche Applied Science, Indianapolis, IN, USA) and SYBER-Green I dye (Roche Diagnostics, Tokyo, Japan) to detect ID1 in bone marrow and peripheral blood. Monitoring was performed according to the manufacturer's instructions, as described earlier (Ogawa et al, 2005). In brief, a master mixture was prepared on ice, containing $1 \mu \mathrm{l}$ of cDNA, $2 \mu \mathrm{l}$ of DNA Master SYBER-Green I mix, $50 \mathrm{ng}$ of primers and $2.4 \mu \mathrm{l}$ of $25 \mathrm{~mm} \mathrm{MgCl}_{2}$. The final volume was adjusted to $20 \mu \mathrm{l}$ with water. After the reaction mixture was loaded into glass capillary tubes, quantitative RT-PCR was performed with the following cycling conditions: initial denaturation at $95^{\circ} \mathrm{C}$ for $10 \mathrm{~min}$, followed by 40 cycles of $95^{\circ} \mathrm{C}$ for $10 \mathrm{~s}$, annealing at $62^{\circ} \mathrm{C}$ for $10 \mathrm{~s}$ and extension at $72^{\circ} \mathrm{C}$ for $10 \mathrm{~s}$. After amplification, products were subjected to a temperature gradient from $67^{\circ} \mathrm{C}$ to $95^{\circ} \mathrm{C}$ at $0.2^{\circ} \mathrm{C} \mathrm{s}^{-1}$, under continuous fluorescence monitoring, to produce a melting curve of products. 


\section{Data analysis for RT-PCR}

We used the LightCycler Software version 3.5 program (Roche Molecular Biochemicals, Basel, Switzerland) to calculate the cycle numbers. After proportional baseline adjustment, a fit point method was used to determine the cycle in which the log-linear signal was first distinguishable from the baseline. This cycle number was used as the crossing point value. A standard curve was produced by measuring the crossing point of each standard value and plotting it against the logarithmic value of the concentration. Concentrations of unknown samples were calculated by plotting their crossing points against the standard curve and dividing by GAPDH content. The results of RT - PCR were sent from Beppu to Tokyo for analyses.

\section{Immunohistochemistry}

Immunohistochemistry was performed on paraffin-embedded specimens obtained from patients with metastatic gastric cancer and two healthy volunteers. Tissue sections were deparaffinised, soaked in $0.01 \mathrm{M}$ sodium citrate buffer and boiled in a microwave for $5 \mathrm{~min}$ at $500 \mathrm{~W}$ to retrieve cell antigens. The primary rabbit polyclonal antibody against ID1 (C-20; Santa Cruz Biotechnology, Santa Cruz, CA, USA), which detects ID1 in paraffin-embedded human tissue sections and does not crossreact with ID2, ID3 or ID4 (Maruyama et al, 1999), was used at a dilution of $1: 100$. The blocking peptide to ID1 (sc-488P, Santa Cruz Biotechnology) was used as a negative control (Supplementary Figure 4). Tissue sections were immunohistochemically stained using the avidinbiotin-peroxidase method (LSAB + system-HRP; DAKO, Kyoto, Japan). All sections were counterstained with haematoxylin.

\section{Statistical analysis}

The expression of ID1 was adjusted in each case for GAPDH expression. For continuous variables, data were expressed as the means \pm s.d. The relationship between ID1 mRNA expression and clinicopathlogical factors was analysed using a $\chi^{2}$ test and Student's $t$-test. All tests were analysed using JMP software (SAS Institute Inc., Cary, NC, USA) and the findings were considered significant when the $P$-value was $<0.05$.

\section{RESULTS}

\section{Expression of ID1 mRNA in bone marrow of gastric cancer}

Figure 1A shows expression of ID1 mRNA in bone marrow according to staging classification. In bone marrow, the mean expression level of ID1 mRNA in stage IV (957 \pm 169$)$ was significantly higher than other stages $(P=0.003)$. Specifically, the levels of stages I, II and III were $54 \pm 185,472 \pm 208$, and $767 \pm 205$, respectively. To confirm the specificity of $I D 1$, we performed RT-PCR analysis of six representative cases in each stage, which was very close to the average value (Figure 1C). In addition, sequencing of these transcripts confirmed that it was the product of ID1 (Supplementary Figure 1).

\section{Expression of ID1 mRNA in peripheral blood of gastric cancer}

In the peripheral blood samples, there was a significant relationship between the expression level of ID1 mRNA and the progression of gastric cancer cases (Figure 1B). The mean expression level of ID1 mRNA in stage IV (105 \pm 15$)$ was significantly higher $(P=0.0001)$ than stages I, II and III $(12.4 \pm 15.4,29.6 \pm 15.5$, and $38.3 \pm 16.0$, respectively). In addition, there was a significant correlation between the expression of ID1
mRNA in bone marrow and peripheral blood ( $r=0.23, P=0.002$, data not shown).

\section{ID1 expression and clinicopathological features of gastric cancer patients}

We examined the clinicopathlogical significance of ID1 mRNA in samples from bone marrow and peripheral blood (Table 1). In both bone marrow and peripheral blood, there are significant associations with many cliniopathlogical features such as tumour size and depth of tumour invasion. Especially, in patients with evidence of lymphatic invasion, lymph node metastasis or peritoneal dissemination, we found significantly higher expression of ID1 mRNA in bone marrow samples compared to patients without metastasis. ( $P=0.001, P=0.001$ and $P=0.002$, respectively, Figures $2 \mathrm{~A}-\mathrm{C}$ ). Similarly, in peripheral blood samples, the cases with lymphatic invasion, lymph node metastasis or peritoneal dissemination had significantly higher expression of ID1 mRNA compared to patients without metastasis. $(P=0.02$, $P=0.02$ and $P<0.0001$ respectively, Figures $3 \mathrm{~A}-\mathrm{C}$ ).

\section{Expression of ID1 protein in bone marrow from patients with metastatic gastric cancer and healthy volunteers}

The ID1 protein expression in bone marrow was evaluated immunohistochemically in studies of metastatic gastric cancer patients and healthy volunteers. In bone marrow of healthy volunteer (Figure 4A), the ID1 expression was localised mainly in the nuclei of bone marrow cells. The population of ID1-positive cells in healthy volunteer is lower than that in metastatic patient (Figure 4B). The ID1 expression of bone marrow cells with metastatic patient was also localised mainly in the nuclei. We also examined the ID1 expression of bone marrow carcinomatosis resulting from gastric cancer. The metastasized cancer cells were confirmed to be epithelial cells by HE (Supplementary Figure 2A) stain and AE1/AE3 (Supplementary Figure 2B). These cells were stained slightly with ID1 antibody in the cytoplasm (Figure 4C).

\section{ID1 expression in primary lesions and metastatic lesions of gastric cancer}

We examined the ID1 protein expression immunohistochemically in 30 primary lesions, 3 metastatic lymph nodes and 3 peritoneal disseminated lesions of gastric cancer cases. We found that 20 cases have high ID1 expression in primary lesions (Figure 5A). Some of the cases showed weak (Supplementary Figure 3A) or moderate (Supplementary Figure 3B) ID1 staining. In addition, two of three metastatic lymph nodes and peritoneal disseminated lesions were stained slightly with the ID1 antibody and the ID1 expression was localised in the cytoplasm of cancer cells in primary lesion, metastatic lymph node metastasis and peritoneal dissemination (Figures $5 \mathrm{~B}$ and $\mathrm{C}$ ).

\section{DISCUSSION}

Peritoneal dissemination is recognised as the most critical factor in assessing the prognosis of gastric cancer cases (Bando et al, 1999). There is no conclusive evidence, however, whether peritoneal dissemination might be established by the lymph node metastasis as well as direct dissemination from the serosal layer of stomach (Yonemura et al, 2007). In this study, the ID1 mRNA expression in bone marrow and peripheral blood was significantly associated with lymph node metastasis and peritoneal dissemination. Therefore, we suggest that peritoneal dissemination of gastric cancer is mediated through lymph node metastasis combined with the ID1-expressing endothelial cells from bone marrow. From a clinical point of view, there are no convincing markers for 
A

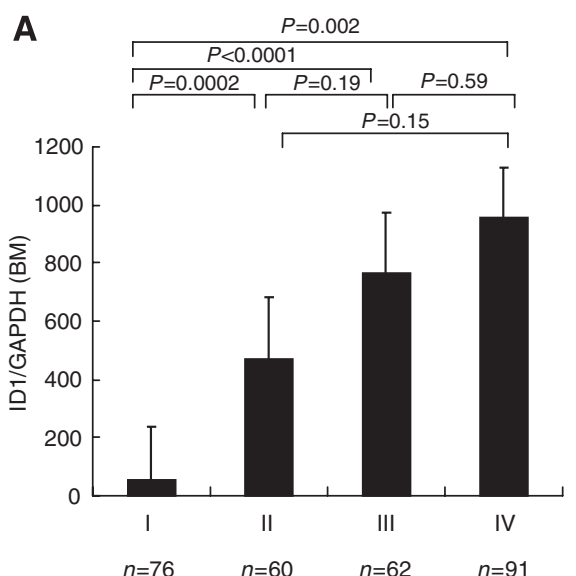

C

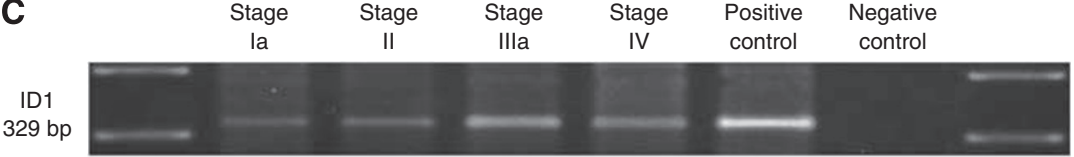

GAPDH

$270 \mathrm{bp}$
B

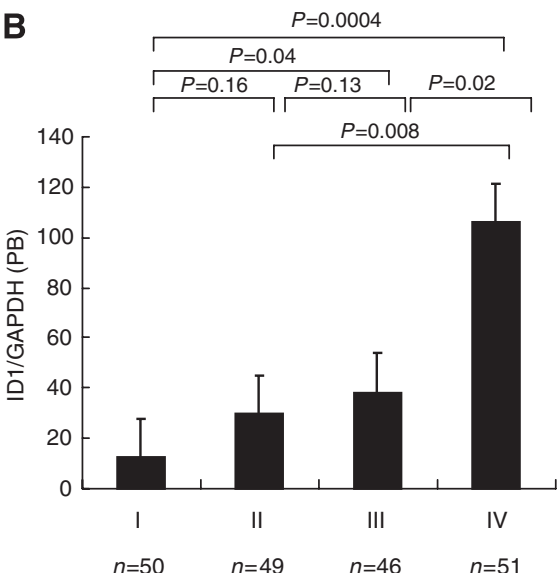

$400 \mathrm{bp}$

$300 \mathrm{bp}$

$300 \mathrm{bp}$

$200 \mathrm{bp}$

Figure I The mean value of ID I mRNA expression normalised GAPDH in bone marrow $(\mathbf{A})$ and peripheral blood (B) according to staging classification. Group stage I consisted of patients with tumours that invaded less than the sub-mucosal layer and no lymph node metastasis (BM: $n=76 ;$ PB: $n=50)$. Group stage II consisted of patients with tumours that penetrated serosa or lymph node metastasis (Group I) (BM: $n=60 ;$ PB: $n=49$ ). Group stage III consisted of patients with tumours invasion of adjacent structures or lymph node metastasis (Group 2 or 3) (BM: n=62; PB: $n=46$ ). Group stage IV consisted of patients with distant metastasis (BM: $n=9$ I; PB: $n=5 \mathrm{I}$ ). The mean value of IDI mRNA expression in bone marrow and peripheral blood increased along with the progression of stage. The RT-PCR analysis of four representative bone marrow samples was performed in each stage (C: upper; ID I product size 329 bp, lower; GAPDH product size $270 \mathrm{bp}$ ).
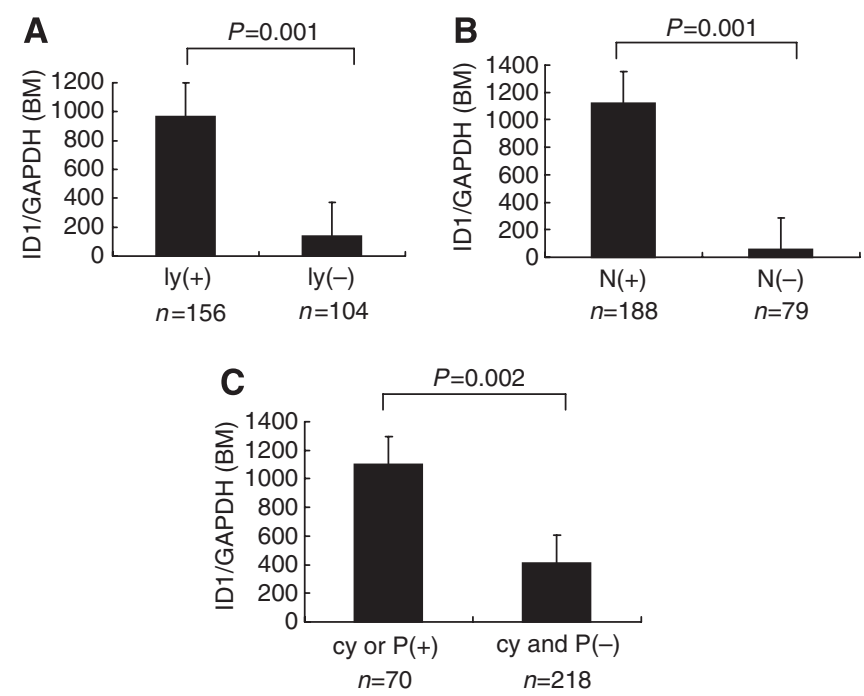

Figure 2 Comparison of the ID I mRNA expression in bone marrow of patients with or without lymphatic invasion (ly) $(+: n=156,-: n=104 ; \mathbf{A})$, lymph node metastasis $(N)(+: n=188,-: n=79 ; \mathbf{B})$ and peritoneal cytology (cy) or peritoneal metastasis $(P)(+: n=70 ;-: n=218 ; \mathbf{C}) . \ln$ patients with evidence of lymphatic invasion, lymph node metastasis or peritoneal dissemination, the expression of ID I mRNA in bone marrow was significantly higher compared to patients without metastasis.

peritoneal dissemination before surgery. Therefore, it is significant that the ID1 expression in bone marrow and peripheral blood can be used as a reliable marker before surgery to determine which
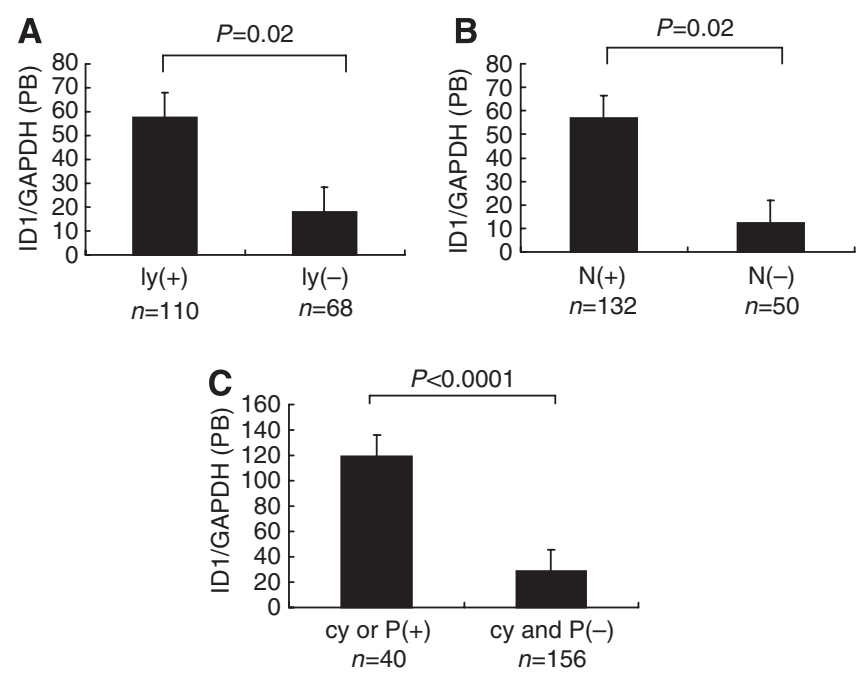

Figure 3 Comparison of the ID I mRNA expression in peripheral blood of patients with or without lymphatic invasion (ly) $(+: n=110,-: n=68$; A) lymph node metastasis $(\mathrm{N})(+: n=132,-: n=50 ; \mathbf{B})$ and peritoneal cytology (cy) or peritoneal metastasis (P) ( $+: n=40,-: n=156$; C). In patients with evidence of lymphatic invasion, lymph node metastasis or peritoneal dissemination, the expression of ID I mRNA in peripheral blood was significantly higher compared to patients without metastasis.

gastric cancer patients are likely to have peritoneal dissemination mediated through lymph node metastasis.

There are two possible sources of the ID1-positive cells: ITC and host cells (such as EPCs, as stated by Gao et al). With regard to tumour cells, Tsuchiya et al showed that the number and size of 

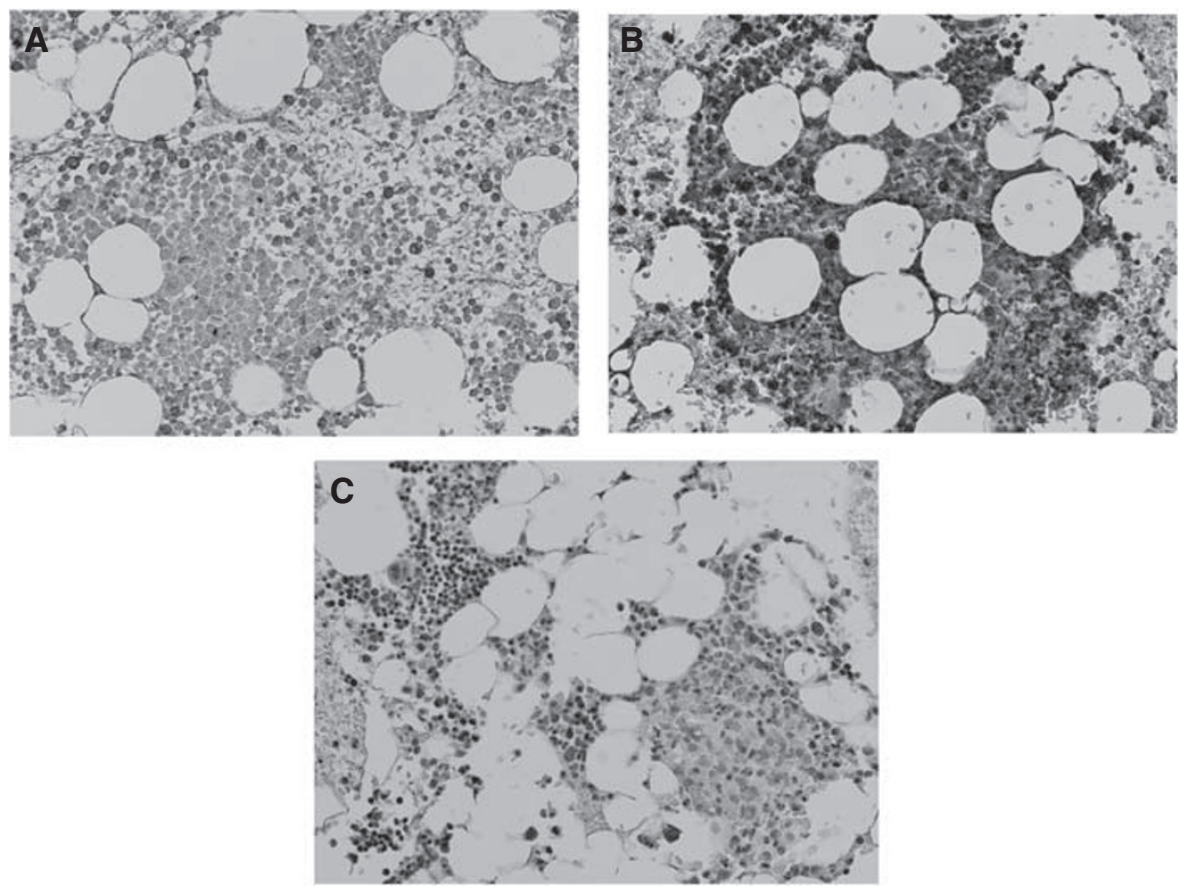

Figure 4 Immunohistochemistry with IDI antibody, assessing bone marrow from a representative healthy volunteer and metastatic gastric cancer patient. In the bone marrow of healthy volunteer $(\mathbf{A})$, the IDI expression was localised mainly in the nuclei of bone marrow cells. The population of IDI-positive cells in healthy volunteer is lower than that in metastatic patients (B). The metastasized cells confirmed to be epithelial cells by HE stain and AEI/AE3 (Supplementary Figures $2 \mathrm{~A}$ and B) that originated from gastric cancer were stained slightly with IDI in cytoplasm $(\mathbf{C})$. $(\mathbf{A}-\mathbf{C}$ : original magnification: $\times$ I00).
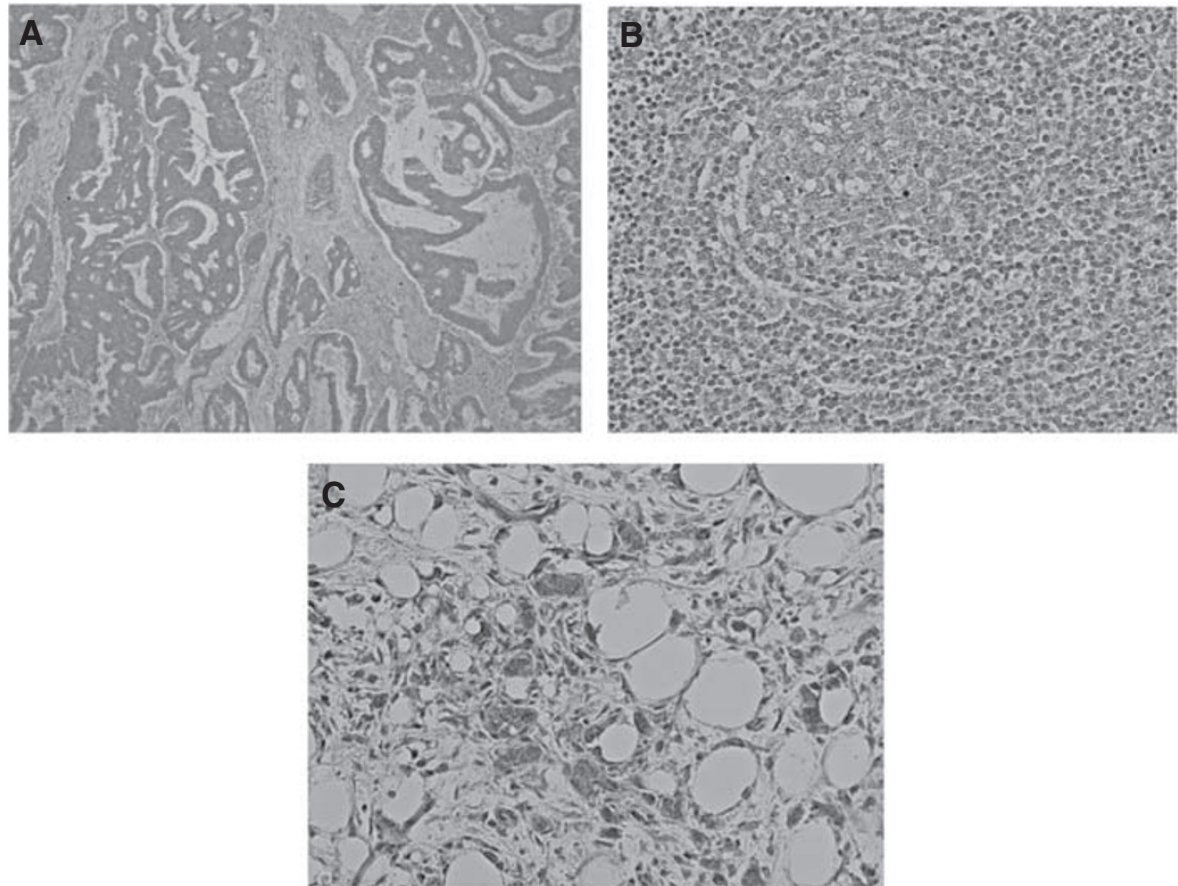

Figure 5 Immunohistochemistry with IDI antibody assessing primary and metastatic lesions. Most of the primary lesions of gastric cancer were stained strongly with the IDI antibody. A representative case was shown in $(\mathbf{A})$. The IDI expression was localised in the cytoplasm of cancer cells in primary lesion, metastatic lymph node metastasis (B) and peritoneal dissemination

(C). (Original magnification: A: $\times 40$, B and $\mathbf{C}: \times 100$ ).

peritoneal metastatic nodules formed by ID1 and ID3 doubleknockdown gastric cancer cells were reduced in comparison to mock-transfected control cells in vivo (Tsuchiya et al, 2005). Furthermore, Kim et al reported that transgenic mice expressing a thymocyte-specific Id1 gene developed T-cell lymphoma in vivo
(Kim et al, 1999). In addition, overexpression of ID1 in the primary cancer cells relative to normal mucosa has been observed in primary human oesophageal ( $\mathrm{Hu}$ et al, 2001) and colorectal cancers (Wilson et al, 2001). Those reports found that the ID1 expression was significantly associated with the differentiation of 
cells and a poor prognosis. In gastric cancer, Han et al found that strong immunohistochemical ID1 expression was associated with poorer differentiation and more aggressive behaviour of tumour cells (Han et al, 2004). In this study, we also examined the ID1 expression in primary lesion of gastric cancer cases. We found that two-thirds cases have high ID1 expression in primary lesions (Figure 5A). Furthermore, we showed that the metastasized cancer cells from gastric cancer in bone marrow were slightly stained with ID1 antibody (Figure 4C). These findings suggest that ID1 may be a potential oncogene. As for the origin of ID1-positive cells in bone marrow, these seem to represent ITCs.

On the other hand, in this study, we present two lines of evidence indicating that the origin of the ID1 expression is from host cells, perhaps originating from bone marrow or peripheral blood. First, immunohistochemical studies showed that the population of ID1-positive cells in healthy volunteer is lower than that in metastatic patients (Figure 4A). Thus, ID1-expressing cells are particularly numerous in the bone marrow in which there are relatively few cancer cells. The current findings may suggest that ID1 is not a component of the aggregated cancer cells in the metastatic lymph nodes and peritoneal disseminated tumours, but instead plays a supportive role for gastric cancer cells to form lymph node metastasis and peritoneal dissemination.

Secondary, Gao et al found that Id1 was expressed by EPC positive for VE-cadherin and CD31 in peripheral blood (Gao et al, 2008). As we expected, the ID1 expression in peripheral blood was significantly related to the incidence of peritoneal dissemination. In addition, there were significant association between ID1 expression in peripheral blood and those in bone marrow from gastric cancer cases. This finding may indicate that the expression of ID1 in peripheral blood originates from the circulating progenitor cells (CPCs), including EPC and from the bone marrow (Lyden et al, 2001). Those results may suggest that the origin of ID1 expression is

\section{REFERENCES}

Bando E, Yonemura Y, Takeshita Y, Taniguchi K, Yasui T, Yoshimitsu Y, Fushida S, Fujimura T, Nishimura G, Miwa K (1999) Intraoperative lavage for cytological examination in 1297 patients with gastric carcinoma. Am J Surg 178: 256-262

Benezra R, Davis RL, Lockshon D, Turner DL, Weintraub H (1990) The protein Id: a negative regulator of helix-loop-helix DNA binding proteins. Cell 61: $49-59$

Fong S, Itahana Y, Sumida T, Singh J, Coppe JP, Liu Y, Richards PC, Bennington JL, Lee NM, Debs RJ, Desprez PY (2003) Id-1 as a molecular target in therapy for breast cancer cell invasion and metastasis. Proc Natl Acad Sci USA 100: 13543 - 13548

Gao D, Nolan DJ, Mellick AS, Bambino K, McDonnell K, Mittal V (2008) Endothelial progenitor cells control the angiogenic switch in mouse lung metastasis. Science 319: 195-198

Han S, Gou C, Hong L, Liu J, ZheyiHan Liu C, Wang J, Wu K, Ding J, Fan D (2004) Expression and significances of Id1 helix-loop-helix protein overexpression in gastric cancer. Cancer Lett 216: 63-71

$\mathrm{Hu}$ YC, Lam KY, Law S, Wong J, Srivastava G (2001) Identification of differentially expressed genes in esophageal squamous cell carcinoma (ESCC) by cDNA expression array: overexpression of Fra-1, Neogenin, Id-1, and CDC25B genes in ESCC. Clin Cancer Res 7: $2213-2221$

Iinuma H, Okinaga K, Egami H, Mimori K, Hayashi N, Nishida K, Adachi M, Mori M, Sasako M (2006) Usefulness and clinical significance of quantitative real-time RT-PCR to detect isolated tumor cells in the peripheral blood and tumor drainage blood of patients with colorectal cancer. Int J Oncol 28: 297-306

Kaplan RN, Riba RD, Zacharoulis S, Bramley AH, Vincent L, Costa C, MacDonald DD, Jin DK, Shido K, Kerns SA, Zhu Z, Hicklin D, Wu Y, Port JL, Altorki N, Port ER, Ruggero D, Shmelkov SV, Jensen KK, Rafii S, Lyden D (2005) VEGFR1-positive haematopoietic bone marrow progenitors initiate the pre-metastatic niche. Nature 438: 820-827

Kim D, Peng XC, Sun XH (1999) Massive apoptosis of thymocytes in T-celldeficient Id1 transgenic mice. Mol Cell Biol 19: 8240-8253 not only from cancer cells but also from host cells, such as CPCs in bone marrow and peripheral blood.

In summary, we found that the ID1 mRNA expression in bone marrow and peripheral blood is a reliable predictive marker for lymph node metastasis and peritoneal dissemination, which indicates a poor prognostic outlook in gastric cancer. In addition, our findings suggest that the ID1 expression originates from not only the cancer cells but also the host side progenitor cells with the cancer-bearing condition. Therefore, we propose that targeting the ID1-expressing cells in the bone marrow and/or peripheral blood after surgery represents a new concept for the treatment and/or prevention of metastasis.

\section{ACKNOWLEDGEMENTS}

We thank T Shimooka, K Ogata, M Kasagi, Y Nakagawa and T Kawano for their technical assistance. This work was supported in part by the following grants and foundations: CREST, Japan Science and Technology Agency (JST); Japan Society for the Promotion of Science (JSPS) Grant-in-Aid for Scientific Research, grant numbers 17109013, 18659384, 18390367, 18590333, 18015039, 19591509, 19390336, 20390360, 20591547, 20790961 and 20790960; The Ministry of Education, Culture, Sports, Science and Technology (MEXT) Grant-in-Aid for Scientific Research on Priority Areas, grant number 18015039; Third Term Comprehensive Tenyear Strategy for Cancer Control, grant number 16271201; NEDO (New Energy and Industrial Technology Development Organization) Technological Development for Chromosome Analysis.

Supplementary Information accompanies the paper on British Journal of Cancer website (http://www.nature.com/bjc)

Lyden D, Hattori K, Dias S, Costa C, Blaikie P, Butros L, Chadburn A, Heissig B, Marks W, Witte L, Wu Y, Hicklin D, Zhu Z, Hackett NR, Crystal RG, Moore MA, Hajjar KA, Manova K, Benezra R, Rafii S (2001) Impaired recruitment of bone-marrow-derived endothelial and hematopoietic precursor cells blocks tumor angiogenesis and growth. Nat Med 7: 1194-1201

Maruyama H, Kleeff J, Wildi S, Friess H, Buchler MW, Israel MA, Korc M (1999) Id-1 and Id-2 are overexpressed in pancreatic cancer and in dysplastic lesions in chronic pancreatitis. Am J Pathol 155: 815-822

Maruyama K, Kaminishi M, Hayashi K, Isobe Y, Honda I, Katai H, Arai K, Kodera Y, Nashimoto A (2006) Gastric cancer treated in 1991 in Japan: data analysis of nationwide registry. Gastric Cancer 9: 51-66

Mimori K, Fukagawa T, Kosaka Y, Kita Y, Ishikawa K, Etoh T, Iinuma H, Sasako M, Mori M (2008) Hematogenous metastasis in gastric cancer requires isolated tumor cells and expression of vascular endothelial growth factor receptor-1. Clin Cancer Res 14: 2609-2616

Mori M, Mimori K, Inoue H, Barnard GF, Tsuji K, Nanbara S, Ueo H, Akiyoshi T (1995) Detection of cancer micrometastases in lymph nodes by reverse transcriptase-polymerase chain reaction. Cancer Res 55: $3417-3420$

Ogawa K, Utsunomiya T, Mimori K, Tanaka F, Inoue $\mathrm{H}$, Nagahara $\mathrm{H}$, Murayama S, Mori M (2005) Clinical significance of human kallikrein gene 6 messenger RNA expression in colorectal cancer. Clin Cancer Res 11: $2889-2893$

Tsuchiya T, Okaji Y, Tsuno NH, Sakurai D, Tsuchiya N, Kawai K, Yazawa K, Asakage M, Yamada J, Yoneyama S, Kitayama J, Osada T, Watanabe T, Tokunaga K, Takahashi K, Nagawa H (2005) Targeting Id1 and Id3 inhibits peritoneal metastasis of gastric cancer. Cancer Sci 96: 784-790

Wilson JW, Deed RW, Inoue T, Balzi M, Becciolini A, Faraoni P, Potten CS Norton JD (2001) Expression of Id helix-loop-helix proteins in colorectal adenocarcinoma correlates with p53 expression and mitotic index. Cancer Res 61: 8803-8810

Yonemura Y, Endo Y, Obata T, Sasaki T (2007) Recent advances in the treatment of peritoneal dissemination of gastrointestinal cancers by nucleoside antimetabolites. Cancer Sci 98: 11-18 